Asian Pacific Journal of Reproduction

Journal homepage: www.apjr.net

\title{
Improvement of sexual behavior, sperm quantity and quality by Quercetin in
} streptozotocin-induced diabetic erectile dysfunction

\author{
Abdulaziz Al-Roujayee ${ }^{凶}$ \\ Department of Dermatology and Venereology, College of Medicine, A1-Imam Mohammad Ibn Saud Islamic University, P.O. Box 11623, Riyadh, \\ Saudi Arabia
}

\section{ARTICLE INFO}

Article history:

Received 10 November 2016

Revision 12 December 2016

Accepted 20 December 2016

Available online 1 January 2017

\section{Keywords:}

Quercetin

Streptozotocin

Sexual dysfunction

Spermatogenesis

\begin{abstract}
Objective: To evaluate the effect of Quercetin (QT) on erectile dysfunction and oxidative stress in penile tissue of streptozotocin-induced diabetic rats. Methods: Two weeks after diabetes induction, QT was treated to normal and diabetic rats for $5 \mathrm{wk}$. Sexual behavioral parameters including mount latency, intromission latency, ejaculation latency, post-ejaculatory interval, mount frequency and intromission frequency, were observed against stimulus females. Sperm count and their motility and viability were recorded. Serum glucose and testosterone levels were estimated. In penile tissue levels of cyclic guanosine monophosphate, thiobarbituric acid reactive substances and glutathione, and enzymatic activities of superoxide dismutase and catalase were measured. Histopathological changes were evaluated in a cross-section of penile tissue. Results: Sexual behavioral ejaculation latency, post-ejaculatory interval, mount latency and intromission latency were significantly increased while mount frequency and intromission frequency were decreased in diabetic rats. Treatment with QT corrected the male sexual behavioral levels and also enhanced the inhibited sperm count, motility and viability in diabetic rats. Serum testosterone and penile cyclic guanosine monophosphate levels were significantly increased in QT treated diabetic rats compared to untreated diabetic animals. Penile oxidative stress biomarkers were corrected by the QT treatments in diabetic rats. Histopathological evaluation revealed damaged penile tissues in diabetic rats, which was protected following QT treatment. Conclusions: QT eliminated the diabetic-induced sexual impairment and showed significant antioxidant effects in penile tissue. Further experimental studies are recommended for QT therapeutically usage.
\end{abstract}

\section{Introduction}

Diabetic-induced erectile dysfunction (ED) found a common clinical problem in male diabetic patients and that has destructive effects on their sexual life. Epidemiological studies revealed that, around $75 \%$ of diabetic patients come across with major complications in their earlier age compared to normal population[1,2]. Experimental and clinical studies have established that, diabeticinduced ED has multifactorial characteristics, involving largely of vascular and neurological insults as a result of diabetic-induced metabolic inequities[3,4]. In diabetic condition boost the expression

Corresponding author: Abdulaziz Al-Roujayee, Department of Dermatology and Venereology, College of Medicine, A1-Imam Mohammad Ibn Saud Islamic University, P.O. Box 11623, Rivadh, Saudi Arabia.

E-mail: abdulazizr73@gmail.com of arginase enzyme, which decreases the availability of L-arginine as substrate to reduce the synthesis of nitric oxide (NO). Moreover, denovo diacyglycerol production promotes the protein kinase $\mathrm{C}$, leading to generation of reaction oxygen species (ROS). Scarano, et al.[5] reported that diabetic mellitus (DM) causes infertility by following the effects on ejaculatory process that can be enlightened through a secondary complication of DM-induced neuropathy an autonomic syndrome[6]. Such pathological condition affects

This is an open access article distributed under the terms of the Creative Commons Attribution-Non Commercial-Share Alike 3.0 License, which allows others to remix tweak and buid upon the work non-commercially, as long as the author is credited and the new creations are licensed under the identical terms.

For reprints contact: reprints@medknow.com

C2017 Asian Pacific Journal of Reproduction Produced by Wolters Kluwer- Medknow

How to cite this article: Abdulaziz Al-Roujayee. Improvement of sexual behavior, sperm quantity and quality by Quercetin in streptozotocin-induced diabetic erectile dysfunction. Asian Pac J Reprod 2017; 6(1): 6-12. 
autonomic neurotransmissions which are intricate in ejaculation process and also affect vas deferens and epididymis where these two organs are important for sperm transportation via the male reproductive tract.

Chronic hyperglycemic conditions generate the ROS and nitrogen species which induces the development of advanced glycation end-product. Consecutively, this may produce variations in the bioavailability in endothelial-and neuronal-derived NO, which may damage the mechanisms of vasorelaxation in corpus cavernosum of diabetic patients[7,8]. In cellular membrane, the ROS production forms a toxic molecule called malondialdehyde which induces the peroxidation of cellular membranes as well as oxidative injury in vivo. The superoxide dismutase (SOD) is also a vital enzyme that eradicates the superoxide radicals. However, increased production of ROS can inhibit SOD activity, which augment the peroxynitrite and ameliorate NO levels[9].

The accumulation of ROS cause changes in penile vasorelaxation by reducing antioxidant levels, lipid peroxidation. Furthermore, DNA damage also may directly cause abnormality in cavernosal cellular structure and function[10,11]. Several preclinical studies recommended the use of antioxidants to eliminate the deleterious effects of ROS in form of ED by showing reduction in superoxide production $\left(\mathrm{O}_{2}^{-}\right)$and increase endothelial NO synthase[8,10-12]. Effect of ROS generation in diabetic penile tissue revealed the $\mathrm{O}_{2}$ production and compared its significance related to diabetic-induced $\mathrm{ED}[8,9]$. However, another important ROS molecule, namely $\mathrm{H}_{2} \mathrm{O}_{2}$, has not been assessed in diabetic cavernosum; $\mathrm{H}_{2} \mathrm{O}_{2}$ is a powerful oxidizing agent, produced after spontaneous or SOD-catalyzed mutation of $\mathrm{O}_{2}^{-}$, as well as by other enzymatic reactions[12].

Flavonoids, known to have antioxidant properties are commonly available in dietary resources. Experimental and clinical studies are reported their pharmacological importance by showing potential action against chronic diseases including DM, hypertension, inflammation and allergy[13]. Quercetin (QT) is one of such natural flavonoid mainly occurring in form of glycosidic as rutin[14]. Naturally, onions, apples, tea and red wine are rich with QT[15]. Furthermore, QT is widely used in herbal remedies and multivitamin supplements[16]. Kanter, et al.[17] and Al-Khamees[18] were reported that QT has attenuated testicular oxidative damage in streptozotocin (STZ)-induced hyperglycemia in rats. Thus, the existing investigation was designed to examine the potential effects of QT against diabeticinduced sexual impairments by alleviating oxidative stress in cavernosum tissues.

\section{Materials and methods}

\subsection{Animals}

This study was conducted using adult Wistar albino rats, provided by the Experimental Animal Care Center, College of Pharmacy, King
Saud University. The experiment started after $7 \mathrm{~d}$ of acclimatization under controlled conditions. The current study protocol was in agreement with the 8th edition of the National Institute of Health (NIH) guidelines for the care and use of laboratory animals and was ethically approved by the ethical committee at the Experimental Animal Care Centre, College of Pharmacy, King Saud University.

\subsection{Diabetes induction}

Animals were subjected to a single IP shoot of a freshly prepared $0.1 \mathrm{~mol} / \mathrm{L}$ citrate buffered STZ solution (Sigma-Aldrich, ST. Louis, MO, USA). The $\mathrm{pH}$ of the solution was 4.5 and dose was delivered at $65 \mathrm{mg} / \mathrm{kg}$. Control animals received the same volume of STZ vehicle. The experimental diabetes was confirmed $48 \mathrm{~h}$ following the STZ injection by measuring the fasting glucose values in blood samples obtained from the tail vein. The diabetic animals considered with $>250 \mathrm{mg} / \mathrm{dL}$ of fasting glucose levels.

\subsection{Study design}

Animals were divided into six groups with six rats in each group as follows:

1) Control animals were treated with vehicle/d (Control)

2) Normal rats were treated with QT $25 \mathrm{mg} / \mathrm{kg} / \mathrm{d}$ (QT25)

3) Normal rats were treated with QT $50 \mathrm{mg} / \mathrm{kg} / \mathrm{d}$ (QT50)

4) Diabetic rats were treated with vehicle/day (STZ)

5) Diabetic rats were treated with RT $25 \mathrm{mg} / \mathrm{kg} / \mathrm{d}$ (QT25+STZ)

6) Diabetic rats were treated with RT $50 \mathrm{mg} / \mathrm{kg} /(\mathrm{QT} 50+\mathrm{STZ})$

The animals in QT groups received freshly prepared QT suspension in $0.25 \%$ carboxymethyl cellulose sodium solution once a day orally (gavage) for $5 \mathrm{wk}$ starting from $2 \mathrm{wk}$ after STZ injection. The equal volume of carboxymethyl cellulose sodium solution was used as vehicle. Weekly, body weights were recorded and at the end of the treatment, sexual behavior was observed by taking stimulus females. Then after overnight fasting, cardiac puncture was done for each animal to collect the blood samples under light ether anesthesia. These samples were centrifuged at $4000 \mathrm{r} / \mathrm{min}$ for $10 \mathrm{~min}$ serum was suppurated in labeled sample and stored at $-20{ }^{\circ} \mathrm{C}$ till analysis. Finally, animals were decapitated and the reproductive organs such as penile tissue, cauda epididymides and seminal vesicles were dissected, weighed and stored at $-80{ }^{\circ} \mathrm{C}$. A cross-section of penile tissue from every group was preserved in $10 \%$ formalin solution for histopathology.

\subsection{Mating behavior tests}

Before diabetic induction, the sexual behavior of the animals was verified to select the sexually active ones to conduct the experiment. Twenty four hours after the treatment period sexual behavioral progress was observed under dim red illumination in a cage with glass frontal wall. Estrus levels were increased in the females 
animals using i.p. injection of estradiol benzoate[19]. Acclimation of males to the test chamber was allowed before the test and the test was taken negative when there was no mount noticed within the next $10 \mathrm{~min}$. Sexual behavioral parameter as earlier described and identified by Ahlenius, et al.[20] including Ejaculation latency (EL), intromission latency (IL), Post-ejaculatory (PEI), mount latency (ML), mount frequency (MF), intromission frequency (IF) were recorded.

\subsection{Evaluation of count, motility and viability}

The spermatozoa samples were acquired from the cauda epididymis and vas deferens and preserved in $1 \mathrm{~mL}$ of modified Krebs Ringerbicarbonate buffer ( $\mathrm{pH} \mathrm{7.4)}$ for $10 \mathrm{~min}$ in $37{ }^{\circ} \mathrm{C}$. The samples were assessed for sperm content, \% motility and sperm viability by using Sperm Class Analyzer (Microptic Diagnostic System, Barcelona, Spain).

\subsection{Penile tissue biochemistry}

In the homogenates of penile tissues, cyclic GMP was determined by the immunoassay kit (R\&D Systems, USA), while the TBARS concentrations were assayed as malondialdehyde equivalent using Zepto Metrix kits. The technique equipped to quantify penile GSH levels was provided by Sedlak and Lindsay[21]. Penile antioxidant enzymes activities including SOD and CAT were respectively estimated by Kono[22] and Aebi[23] methods. A spectrophotometer (LKB-Pharmacia, Mark II, Ireland) was to read the colorimetric biochemical results.

\subsection{Histopathological procedures}

Across sectional portion of a penile tissue from each group of treatment were preserved in $10 \%$ buffered formalin. After embedding the samples in paraffin blocks, they were sectioned into a thickness $5 \mu \mathrm{m}$ using an optical rotary microtome. The produced sections were then stained with H \& E stain. The histological examination of the stained samples was conducted in a blind fashion.

\subsection{Statistical analysis}

Achieved data expressed as means \pm SE. All the statistical calculations were made by using Graph Pad Prism (version 5) software. Statistical significances were carried out by Tukey-post hoc test considering $P<0.05$ is significant.

\section{Results}

In diabetic rats, EL, PEI, ML and IL latencies increased significantly $(P<0.001)$ while MF and IF frequencies were inhibited $(P<0.001)$ compared to control animals. QT treatment with the higher doses to the diabetic rats markedly inhibited the latency time as compared to untreated diabetic animals. The mounting and intromission frequencies were markedly $(P<0.001)$ lowered in diabetic animals compared to normal animals. Administration of the higher dose of QT to diabetic rats significantly enhanced the MF $(P<0.01)$ and IF $(P<0.05)$ frequency time (seconds) compared to untreated diabetic group (Figure 1).

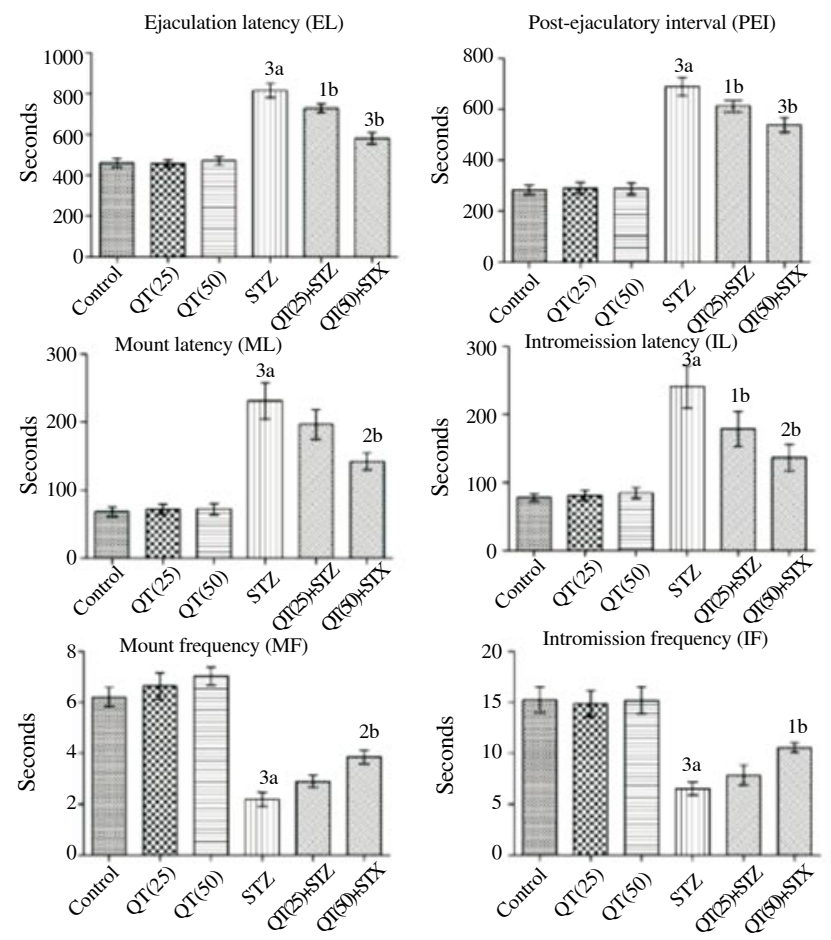

Figure 1. Effect of QT on sexual behavioral parameters including ML, IL, EL, PEI, MF and IF of normal and diabetic rats.

Results were expressed as mean \pm SE $(n=6)$ and statistically analyzed by one-way ANOVA followed by Tukey-post hoc test. ${ }^{1} P<0.05,{ }^{2} P<0.01$ and ${ }^{3} P<0.001$. 'a' indicates control group vs STZ, QT(25) and QT(50) groups, while 'b' indicates STZ group vs. QT(25)+STZ and QT(50)+STZ groups.

Total sperm count was considerably $(P<0.001)$ decreased in diabetic rats and that found significantly $(P<0.05)$ increased in QT $(50 \mathrm{mg} / \mathrm{kg} / \mathrm{d})$ treated animals compared to untreated diabetic animals. Motility and Viability percentages were also inhibited $(P<0.001)$ in diabetic rats compared to control group. Higher dose of QT treatment to diabetic rats enhanced the percentage inhibition $(P<0.05)$ of motility and viability while compared to untreated diabetic animals (Figure 2).

STZ-induced hyperglycemia was markedly $(P<0.05)$ lowered by the QT $(50 \mathrm{mg} / \mathrm{kg} / \mathrm{d})$ for $5 \mathrm{wk}$ compared to the STZ group. Serum testosterone levels were significantly $(P<0.001)$ inhibited in diabetic animals as compared to normal values. Treatments with lower and higher doses of QT to diabetic rats markedly $P<0.05$ and $P<0.01$ 
Sperm count

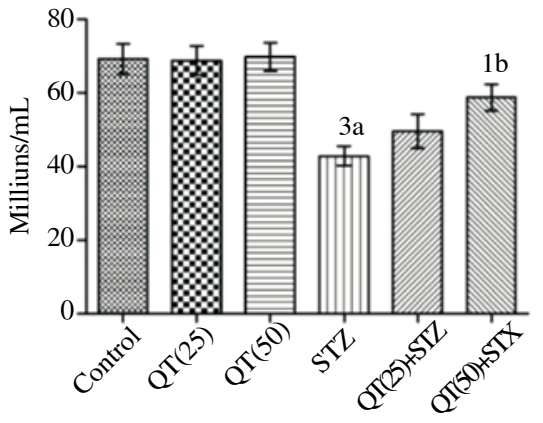

Sperm motility

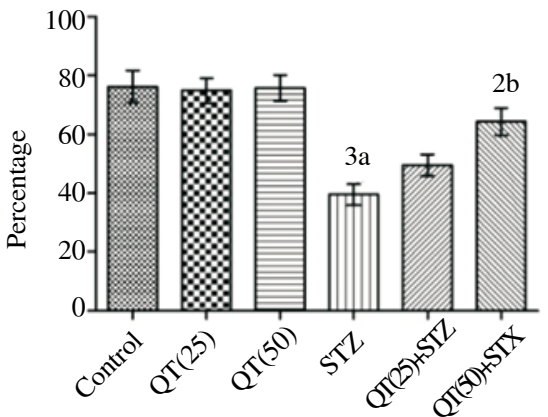

Sperm viability

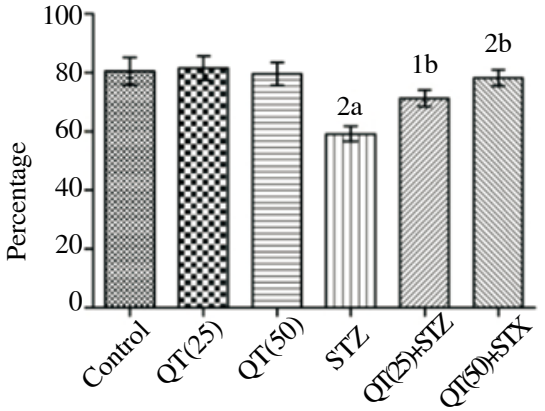

Figure 2. Effect of QT on sperm count, sperm motility and sperm viability of normal and diabetic rats.

Results were expressed as mean \pm SE $(n=6)$ and statistically analyzed by one-way ANOVA followed by Tukey-post hoc test. ${ }^{1} P<0.05,{ }^{2} P<0.01$ and ${ }^{3} P<0.001 .{ }^{a}$ indicates control group vs. STZ, QT(25) and QT(50) groups, while 'b' indicates STZ group vs. QT(25)+STZ and QT(50)+STZ groups.

enhanced the serum testosterone levels compared to STZ group (Figure 3).

Blood Glucose

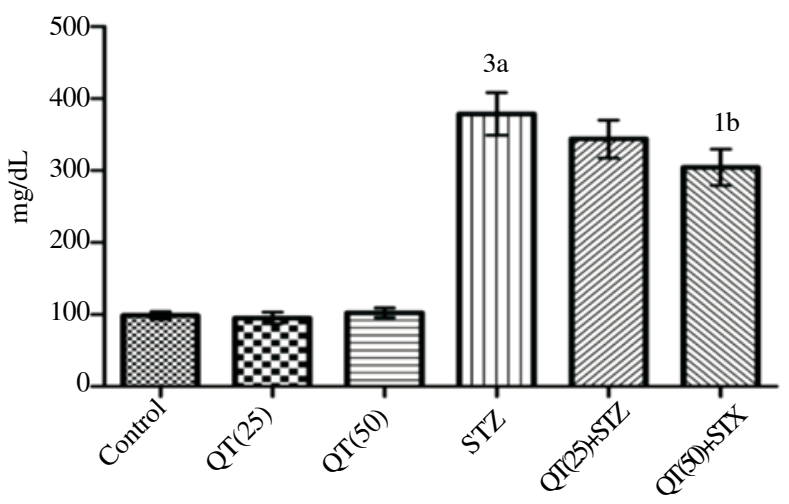

Testosterone

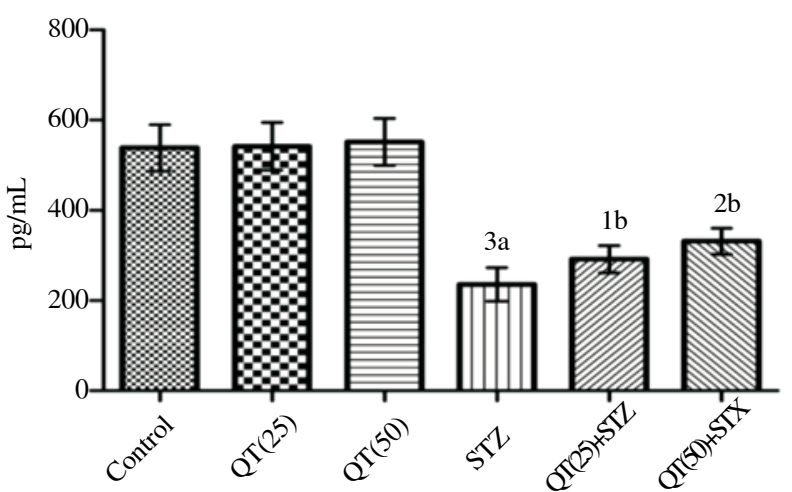

Figure 3. Effect of QT on serum blood glucose and testosterone levels of normal and diabetic rats.

Results were expressed as mean $\pm \mathrm{SE}(n=6)$ and statistically analyzed by one-way ANOVA followed by Tukey-post hoc test. ${ }^{1} P<0.05,{ }^{2} P<0.01$ and ${ }^{3} P<0.001$. ${ }^{\text {a' }}$ indicates control group vs. STZ, QT(25) and QT(50) groups, while ${ }^{\text {'b }}$ indicates STZ group vs. QT(25)+STZ and QT(50)+STZ groups.

Penile cGMP levels in diabetic rats were significantly $(P<0.01)$ inhibited compared to controls. Treatments with higher the dose $(50 \mathrm{mg} / \mathrm{kg} / \mathrm{d})$ of QT to diabetic rats for 5 wk significantly $(P<0.05)$ enhanced the penile cGMP levels compared to untreated diabetic rats (Figure 4).

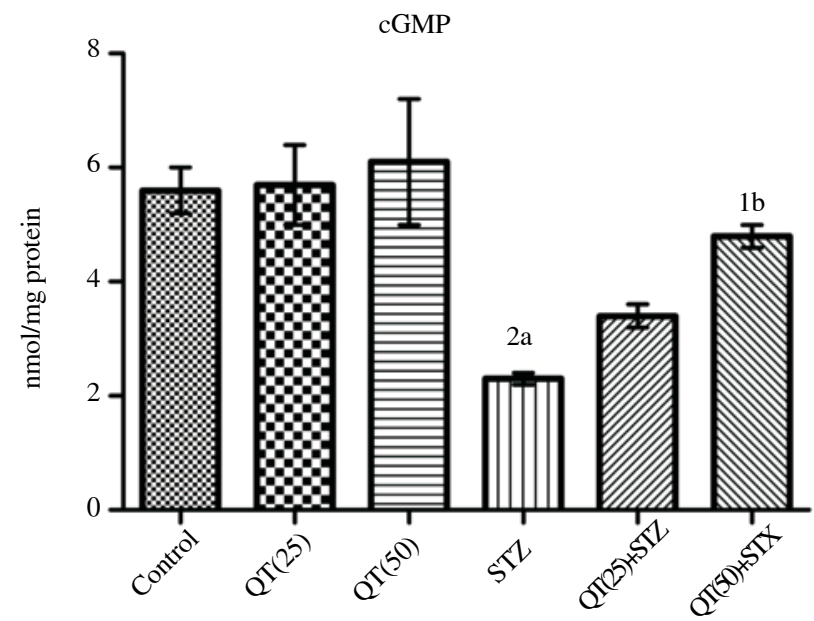

Figure 4. Effect of quercetin (QT) on penile levels of cGMP in normal and diabetic rats.

Results were expressed as mean \pm SE $(n=6)$ and statistically analyzed by one-way ANOVA followed by Tukey-post hoc test. ${ }^{1} P<0.05,{ }^{2} P<0.01$ and ${ }^{3} P<0.001$. ' ${ }^{a}$ indicates control group $v s$. STZ, QT(25) and QT(50) groups, while 'b' indicates STZ group vs. QT(25)+STZ and QT(50)+STZ groups.

Oxidative biomarkers showed significant changes in penile tissue of diabetic rats. The TBARS levels increased from $(2.78 \pm 0.31)$ $\mathrm{nmol} / \mathrm{mg}$ protein to $(6.34 \pm 0.78) \mathrm{nmol} / \mathrm{mg}$ protein while GSH levels decreased from $(7.84 \pm 0.94) \mathrm{nmol} / \mathrm{mg}$ protein to $(3.87 \pm 0.27) \mathrm{nmol} /$ $\mathrm{mg}$ protein in penile tissue of diabetic rats. Similarly, enzymatic activities of SOD and catalase were markedly $(P<0.001)$ attenuated in the penile tissue of the diabetic untreated animals compared to their respective untreated control ones. Treatment with higher dose $(50 \mathrm{mg} / \mathrm{kg} / \mathrm{d})$ or QT to diabetic rats for $5 \mathrm{wk}$ potentially $(P<0.05)$ eliminated the diabetic-induced alterations in oxidative stress biomarkers (Figure 5). 
TBARS
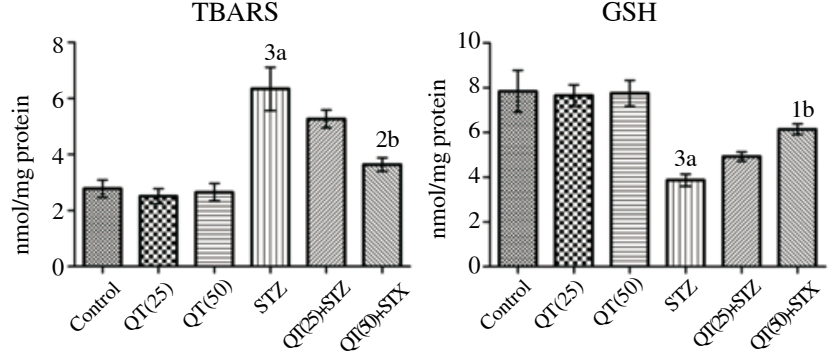

SOD

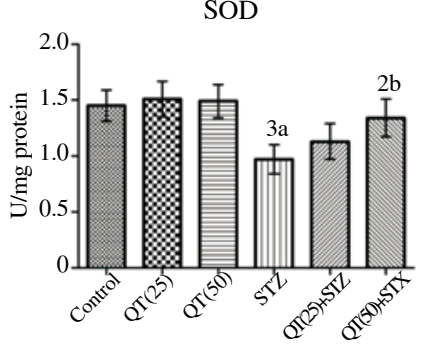

CAT

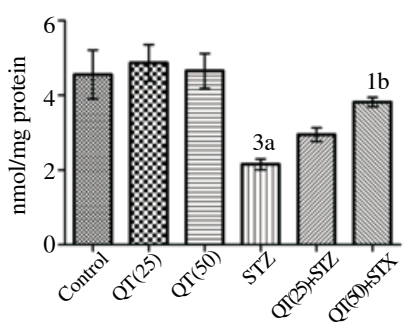

Figure 5. Effect of QT on levels of thiobarbituric acid reaction substance, glutathione (GSH), SOD and catalase in penile tissue of normal and diabetic rats. Results were expressed as mean \pm SE $(n=6)$ and statistically analyzed by one-way ANOVA followed by Tukey-post hoc test. ${ }^{1} P<0.05,{ }^{2} P<0.01$ and ${ }^{3} P<0.001$. 'a' indicates control group $v$ STZ, QT(25) and QT(50) groups, while 'b' indicates STZ group vs QT(25)+STZ and QT(50)+STZ groups.

Histopathological investigation of the penis tissue showed (A) cross sections covered by skin underneath which normal erectile tissue formed of numerous blood vessels lined by flat epithelium. Corpora cavernosa and spongiosa are normal with no significant inflammatory reaction in the control group; (B) Corpora cavernosa covered by cuboidal epithelial cells and numerous blood vessels lined by flat epithelium with scattered inflammatory cells in the diabetic group; (C) vascular subcutaneous tissue with numerous small blood vessels lined by flat epithelial cells. The corpora cavernosa showed some destruction in the tissue, while corpora spongiousum is normal in higher dose (50 mg/kg/d) QT treated group (Figure 6).

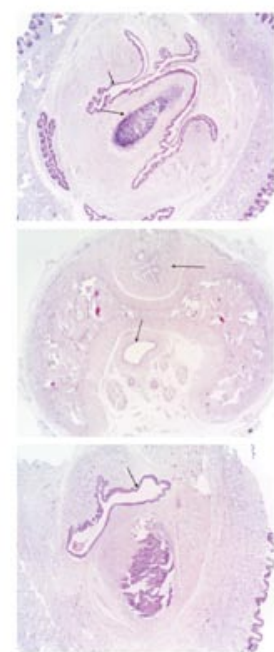

$4 \times$

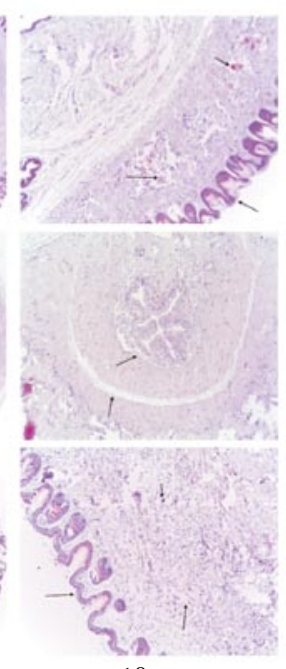

$10 \times$

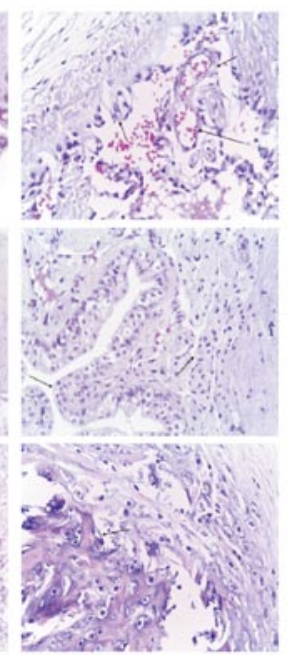

$40 \times$

Figure 6. Histopathological features of penis tissues of (A) control, (B) diabetic untreated and $(\mathrm{C})$ diabetic QT treated rats.

Figure with different magnification showing almost normal features with few scattered inflammatory cells in diabetic untreated group and some corpora cavernosa destruction in diabetic QT treated group.

\section{Discussion}

Present data revealed the beneficial properties of QT on STZinduced erectile dysfunction in Wistar rats. We found marked reduction in sexual performance of diabetic rats compared to controls. Five weeks of QT treatment to diabetic animals considerably enhanced the sexual activity by reducing the EL, PEI, ML and IL latencies while enhancing the MF and IF frequencies. Diabetes induced significant oxidative impairments in the penile cells. Administration of QT to diabetic rats markedly reduced the penile cellular damage and its oxidative stress induced by DM. Our histopathological screening further confirms the potential properties of QT against hyperglycemia-induced damage in penile tissue.

Epidemiological studies showed the higher prevalence of severe ED in diabetic men compared to normal healthy males[1,2]. Experimentally-induced diabetic models are well-established to elaborate the mechanism of diabetic-induced ED and also a recommended model for establishing the beneficial effect of any new compound against diabetes ED[9]. In present study, sever sexual impairment was found in STZ-induced diabetic rat by inhibiting the EL, PEI, ML and IL latencies and increasing the MF and IF frequencies. Our observations are in harmony with other reports, which showed fewer in sexual behaviors of diabetic animals compared controls[5]. In QT supplemented diabetic rats, we found the characteristics of all sexual behavioral tests enhanced, suggesting that QT produces protective action in one of the diabetic-induced metabolic syndrome.

It is well established that the testosterone levels decreases in diabetic conditions. However, testosterone depletion is not only a factor for reduction in the mating behavior because it has seen its replacement could not improve the diabetic-induced adverse effects on sexual behavior. However, hyperglycemia-provoked sexual imbalance may be a result of the inhibition of testosterone, by the direct or indirect actions of insulin and/or glucose on the adrenergic complex[24]. Our findings also demonstrated a significant decrease in testosterone levels compared to control group in serum. The QT treatment markedly increased the inhibited testosterone levels in our diabetic rats which showed potentials of QT against diabeticinduced ED. Zhang and his colleagues[10] studied the QT effect on intracavernous pressure of STZ-induced diabetic rats and clearly documented the potential effect of QT against ED. Earlier reports documented that diabetes causes inhibition in sperm count, motility and viability[5], similar changes have noted in present study. The decreased values of sperm numbers, motility and viability were significantly enhanced by the QT treatment. It supports the beneficial effect of QT against diabetic-induced ED.

Since the evaluation of the conducted mating behavior tests in the current study relayed upon physical observation, further 
biochemical analysis including oxidative stress and inflammatory process were used to explore QT mode of action against diabeticinduced erectile dysfunction. cGMP concentrations were markedly lowered in the current investigation in penile tissues. Similar inhibition was demonstrated experimentally in earlier studies[25,26]. In several preclinical studies it is clearly documented the oxidative impairment in the male reproductive system[27-29]. It is established that hyperglycemia provokes the production of glycation endproducts, reactive oxygen and nitrogen species and impairs no bioavailability and negatively affects penile tissues, resulting in alterations in vasorelaxation mechanisms of the endothelium[7,30]. In one study, the transfer of adenoviral gene bearing EC-SOD lowered the corporal superoxide anion, enhanced the cavernosal cGMP, improved NO bioavailability, and restored the erectile functions in diabetic animals[8]. In the present study, we explored oxidative stress biomarkers including TBARS and GSH levels along with SOD and CAT activities in penile tissues and found decreased GSH levels, suppressed antioxidant enzymes activities and triggered TBARS. These abnormalities were markedly corrected by QT, which suggests it therapeutic value in improving ED in diabetic rats through repairing of oxidative damage in penile tissue. The antioxidant properties of QT are mainly attributed to its chemical structure, which contains multiple hydroxyl groups with antiradical and scavenger activities. Moreover, the chemical structure of QT possesses double bond and carbonyl groups, which stabilize the flavonoid via conjugation and electron delocalization. QT also may undergo one or two electron oxidation to produced metal ions chelating derivatives including semiquinone and quinine type compounds[31].

In summary, we found that diabetic rats exhibited decreased sexual performance sperm count inhibition with low motility, viability, reduced antioxidant enzymes activities, along with elevated lipid peroxidation and inhibited GSH levels. QT treatment might attenuate ED in diabetic animals partly by improvement in sexual performance and suppressing oxidative injury. We recommend further preclinical researches to estimate the utility and usefulness of QT as a new approach in ED.

\section{Conflict of interest statement}

The author declares that he has no conflict of interest.

\section{References}

[1] Maiorino MI, Bellastella G, Esposito K. Diabetes and sexual dysfunction: Current perspectives. Diabetes Metab Syndr Obes 2014; 7: 95-105.

[2] Saenz de Tejada I, Angulo J, Cellek S, Gonzalez-Cadavid N, Heaton
J, Pickard R, et al. Pathophysiology of erectile dysfunction. J Sex Med 2005; 2(1): 26-39.

[3] Brownlee M. The pathobiology of diabetic complications: A unifying mechanism. Diabetes 2005; 54(6): 1615-1625.

[4] Arkkila PE, Koskinen PJ, Kantola IM, Ronnemaa T, Seppanen E, Viikari JS. Diabetic complications are associated with liver enzyme activities in people with type 1 diabetes. Diabetes Res Clin Pract 2001; 52(2): 113-118.

[5] Scarano WR, Messias AG, Oliva SU, Klinefelter GR, Kempinas WG. Sexual behaviour sperm quality and quantity after short-term streptozotocin induced hyperglycemia in rats. Int J Androl 2006; 29(4): 482-488.

[6] Vinik AI, Maser RE, Mitchell BD, Freeman R. Diabetic autonomic neuropathy. Diabetes Care 2003; 26(5): 1553-1579.

[7] Agarwal A, Said TM. Oxidative stress, DNA damage and apoptosis in male infertility: A clinical approach. BJU Int 2005; 95(4): 503-507.

[8] Matsui H, Sopko NA, Hannan JL, Bivalacqua TJ. Mini review: Pathophysiology of erectile dysfunction. Curr Drug Targets 2015; 16(5): 411-419.

[9] Hirata H, Kawamoto K, Kikuno N, Kawakami T, Kawakami K, Sain $\mathrm{S}$, et al. Restoring erectile function by antioxidant therapy in diabetic rats. J Urol 2009; 182(5): 2518-2525.

[10]Zhang R, Kang KA, Kang SS, Park JW, Hyun JW. Morin (2',3,4',5,7pentahydroxyflavone) protected cells against gamma-radiation-induced oxidative stress. Basic Clin Pharmacol Toxicol 2011; 108(1): 63-72.

[11]Tuncayengin A, Biri H, Onaran M, Sen I, Tuncayengin O, Polat F, et al. Cavernosal tissue nitrite, nitrate, malondialdehyde and glutathione levels in diabetic and non-diabetic erectile dysfunction. Int $J$ Androl 2003; 26(4): 250-254.

[12]Yu W, Wan Z, Qiu XF, Chen Y, Dai YT. Resveratrol, an activator of SIRT1, restores erectile function in streptozotocin-induced diabetic rats. Asian J Androl 2013; 15(5): 646-651.

[13]Bischoff SC. Quercetin: Potentials in the prevention and therapy of disease. Curr Opin Clin Nutr Metab Care 2008; 11(6): 733-740.

[14]Havsteen BH. The biochemistry and medical significance of the flavonoids. Pharmacol Ther 2002; 96(2-3): 67-202.

[15]Hertog MG, Feskens EJ, Hollman PC, Katan MB, Kromhout D. Dietary antioxidant flavonoids and risk of coronary heart disease: The zutphen elderly study. Lancet 1993; 342(8878): 1007-1011.

[16]Erlund I, Kosonen T, Alfthan G, Maenpaa J, Perttunen K, Kenraali J, et al. Pharmacokinetics of quercetin from quercetin aglycone and rutin in healthy volunteers. Eur J Clin Pharmacol 2000; 56(8): 545-553.

[17]Kanter M, Aktas C, Erboga M. Protective effects of quercetin against apoptosis and oxidative stress in streptozotocin-induced diabetic rat testis. Food Chem Toxicol 2012; 50(3-4): 719-725.

[18]Alkhamees OA. Quercetin attenuates testicular damage and oxidative stress in streptozotocin-induced diabetic rats. Bri J Pharmacol Toxicol 2014; 5(2): 88-97.

[19]Arteche E, Strippoli G, Loirand G, Pacaud P, Candenas L, Molto JC, et al. An analysis of the mechanisms involved in the okadaic acid-induced 
contraction of the estrogen-primed rat uterus. J Pharmacol Exp Ther 1997; 282(1): 201-207.

[20]Ahlenius S, Larsson K. Apomorphine and haloperidol-induced effects on male rat sexual behavior: No evidence for actions due to stimulation of central dopamine autoreceptors. Pharmacol Biochem Behav 1984; 21(3): 463-466.

[21]Sedlak J, Lindsay RH. Estimation of total, protein-bound, and nonprotein sulfhydryl groups in tissue with Ellman's reagent. Anal Biochem 1968; 25(1): 192-205.

[22]Kono Y. Generation of superoxide radical during autoxidation of hydroxylamine and an assay for superoxide dismutase. Arch Biochem Biophys 1978; 186(1): 189-195.

[23]Aebi H. Catalase. Methods of enzymatic analysis. In: Hans-UIrich bergmeyer. 2nd ed. New York: Elsevier Inc; 1974, p. 674-684.

[24]Kniel PC, Junker U, Perrin IV, Bestetti GE, Rossi GL. Varied effects of experimental diabetes on the autonomic nervous system of the rat. Lab Invest 1986; 54(5): 523-530.

[25]Yang J, Wang T, Rao K, Zhan Y, Chen RB, Liu Z, et al. S-allyl cysteine restores erectile function through inhibition of reactive oxygen species generation in diabetic rats. Andrology 2013; 1(3): 487-494.

[26]Yang R, Wang J, Chen Y, Sun Z, Wang R, Dai Y. Effect of caffeine on erectile function via up-regulating cavernous cyclic guanosine monophosphate in diabetic rats. J Androl 2008; 29(5): 586-591.

[27]Agbaje IM, Rogers DA, McVicar CM, McClure N, Atkinson AB, Mallidis C, et al. Insulin dependant diabetes mellitus: Implications for male reproductive function. Hum Reprod 2007; 22(7): 1871-1877.

[28]Shrilatha B, Muralidhara. Early oxidative stress in testis and epididymal sperm in streptozotocin-induced diabetic mice: Its progression and genotoxic consequences. Reprod Toxicol 2007; 23(4): 578-587.

[29]Amaral S, Moreno AJ, Santos MS, Seica R, Ramalho-Santos J. Effects of hyperglycemia on sperm and testicular cells of Goto-Kakizaki and streptozotocin-treated rat models for diabetes. Theriogenology 2006; 66(9): 2056-2067.

[30]Newsholme P, Haber EP, Hirabara SM, Rebelato EL, Procopio J, Morgan D, et al. Diabetes associated cell stress and dysfunction: Role of mitochondrial and non-mitochondrial ROS production and activity. $J$ Physiol 2007; 583(1): 9-24.

[31]Flora S. Structural, chemical and biological aspects of antioxidants for strategies against metal and metalloid exposure. Oxid Med Cell Longev 2009; 2(4): 191-206. Diabetic erectile dysfunction. Int J Androl 2003; 26(4): 250-254.

[12]Yu W, Wan Z, Qiu XF, Chen Y, Dai YT. Resveratrol, an activator of SIRT1, restores erectile function in streptozotocin-induced diabetic rats. Asian J Androl 2013; 15(5): 646-651.

[13]Bischoff SC. Quercetin: Potentials in the prevention and therapy of disease. Curr Opin Clin Nutr Metab Care 2008; 11(6): 733-740.

[14]Havsteen BH. The biochemistry and medical significance of the flavonoids. Pharmacol Ther 2002; 96(2-3): 67-202.

[15]Hertog MG, Feskens EJ, Hollman PC, Katan MB, Kromhout D. Dietary antioxidant flavonoids and risk of coronary heart disease: The zutphen elderly study. Lancet 1993; 342(8878): 1007-1011.
[16]Erlund I, Kosonen T, Alfthan G, Maenpaa J, Perttunen K, Kenraali J, et al. Pharmacokinetics of quercetin from quercetin aglycone and rutin in healthy volunteers. Eur J Clin Pharmacol 2000; 56(8): 545-553.

[17]Kanter M, Aktas C, Erboga M. Protective effects of quercetin against apoptosis and oxidative stress in streptozotocin-induced diabetic rat testis. Food Chem Toxicol 2012; 50(3-4): 719-725.

[18]Alkhamees OA. Quercetin attenuates testicular damage and oxidative stress in streptozotocin-induced diabetic rats. Bri J Pharmacol Toxicol 2014; 5(2): 88-97.

[19]Arteche E, Strippoli G, Loirand G, Pacaud P, Candenas L, Molto JC, et al. An analysis of the mechanisms involved in the okadaic acid-induced contraction of the estrogen-primed rat uterus. J Pharmacol Exp Ther 1997; 282(1): 201-207.

[20]Ahlenius S, Larsson K. Apomorphine and haloperidol-induced effects on male rat sexual behavior: No evidence for actions due to stimulation of central dopamine autoreceptors. Pharmacol Biochem Behav 1984; 21(3): 463-466.

[21]Sedlak J, Lindsay RH. Estimation of total, protein-bound, and nonprotein sulfhydryl groups in tissue with Ellman's reagent. Anal Biochem 1968; 25(1): 192-205.

[22]Kono Y. Generation of superoxide radical during autoxidation of hydroxylamine and an assay for superoxide dismutase. Arch Biochem Biophys 1978; 186(1): 189-195.

[23]Aebi H. Catalase. Methods of enzymatic analysis. 2nd ed. In: HansUIrich Bergmeyer, editor. New York: Elsevier Inc; 1974, p. 674-684.

[24]Kniel PC, Junker U, Perrin IV, Bestetti GE, Rossi GL. Varied effects of experimental diabetes on the autonomic nervous system of the rat. $\mathrm{Lab}$ Invest 1986; 54(5): 523-530.

[25]Yang J, Wang T, Rao K, Zhan Y, Chen RB, Liu Z, et al. S-allyl cysteine restores erectile function through inhibition of reactive oxygen species generation in diabetic rats. Andrology 2013; 1(3): 487-494.

[26]Yang R, Wang J, Chen Y, Sun Z, Wang R, Dai Y. Effect of caffeine on erectile function via up-regulating cavernous cyclic guanosine monophosphate in diabetic rats. J Androl 2008; 29(5): 586-591.

[27]Agbaje IM, Rogers DA, McVicar CM, McClure N, Atkinson AB, Mallidis $\mathrm{C}$, et al. Insulin dependant diabetes mellitus: Implications for male reproductive function. Hum Reprod 2007; 22(7): 1871-1877.

[28]Shrilatha B, Muralidhara. Early oxidative stress in testis and epididymal sperm in streptozotocin-induced diabetic mice: Its progression and genotoxic consequences. Reprod Toxicol 2007; 23(4): 578-87.

[29]Amaral S, Moreno AJ, Santos MS, Seica R, Ramalho-Santos J. Effects of hyperglycemia on sperm and testicular cells of Goto-Kakizaki and streptozotocin-treated rat models for diabetes. Theriogenology 2006; 66(9): 2056-2067.

[30]Newsholme P, Haber EP, Hirabara SM, Rebelato EL, Procopio J, Morgan D, et al. Diabetes associated cell stress and dysfunction: Role of mitochondrial and non-mitochondrial ROS production and activity. $J$ Physiol 2007; 583(1): 9-24.

[31]Flora S. Structural, chemical and biological aspects of antioxidants for strategies against metal and metalloid exposure. Oxid Med Cell Longev 2009; 2(4): 191-206. 